\title{
From digital literacy to digital competence: the teacher digital competency (TDC) framework
}

\author{
Garry Falloon ${ }^{1}$ \\ Published online: 29 March 2020 \\ (c) The Author(s) 2020
}

\begin{abstract}
Over the years, a variety of frameworks, models and literacies have been developed to guide teacher educators in their efforts to build digital capabilities in their students, that will support them to use new and emerging technologies in their future classrooms. Generally, these focus on advancing students' skills in using 'educational' applications and digitally-sourced information, or understanding effective blends of pedagogical, content and technological knowledge seen as supporting the integration of digital resources into teaching, to enhance subject learning outcomes. Within teacher education institutions courses developing these capabilities are commonly delivered as standalone entities, or there is an assumption that they will be generated by technology's integration in other disciplines or through mandated assessment. However, significant research exists suggesting the current narrow focus on subject-related technical and information skills does not prepare students adequately with the breadth of knowledge and capabilities needed in today's classrooms, and beyond. This article presents a conceptual framework introducing an expanded view of teacher digital competence (TDC). It moves beyond prevailing technical and literacies conceptualisations, arguing for more holistic and broader-based understandings that recognise the increasingly complex knowledge and skills young people need to function ethically, safely and productively in diverse, digitally-mediated environments. The implications of the framework are discussed, with specific reference to its interdisciplinary nature and the requirement of all faculty to engage purposefully and deliberately in delivering its objectives. Practical suggestions on how the framework might be used by faculty, are presented.
\end{abstract}

Keywords Digital competence · Digital literacy $\cdot$ Technology $\cdot$ Integration $\cdot$ Teacher education $\cdot$ TPACK $\cdot$ SAMR

Garry Falloon

garry.falloon@mq.edu.au

1 The Macquarie School of Education, The Faculty of Arts, Macquarie University, Sydney, Australia 


\section{Introduction}

The problem of better-preparing teacher education students to use digital technologies effectively and productively in schools is an enduring issue (Guzman and Nussbaum 2009; Otero et al. 2005; Sutton 2011). Traditionally, teacher education providers have opted for isolated ICT courses or units, often positioned early in the students' qualification programme. These are delivered on the assumption that 'front loading' students with what are perceived as essential knowledge and skills, will support them to complete course assessment requirements - such as developing 'technology integrated' units of learning, for practicum work in schools, and by implication, helping them use digital technology effectively in their later teaching career (Kleiner et al. 2007; Polly et al. 2010). These courses generally focus on building students' confidence and attitudes towards using digital resources in teaching and learning, and developing the requisite hardware and software skills to facilitate this (Foulger et al. 2012).

However, a growing body of research suggests this approach is ineffective for building broader and deeper understandings of the knowledge and capabilities needed by teachers educating students for future life, and it has been criticised for its narrow focus on contextually-devoid, isolated technical skills (e.g., Ferrari 2012; Janssen et al. 2013; Ottestad et al. 2014). While there is general agreement about the need to develop and implement alternative approaches to teacher preparation that reflect a more holistic and integrated approach that addresses students' concerns of "a disconnect between their technology training and the rest of their teacher preparation program" (Sutton 2011, p. 43), debate exists about exactly how this should be done, and what programmes of this nature should comprise.

\section{Digital literacy or digital competence?}

Traditional approaches to developing digital capabilities in teacher education have focused on promoting students' 'digital literacy' (Borthwick and Hansen 2017). This term first emerged around 1997, when Paul Gilster introduced it in his book as:

.... a set of skills to access the internet, find, manage and edit digital information; join in communications, and otherwise engage with an online information and communication network. Digital literacy is the ability to properly use and evaluate digital resources, tools and services, and apply it to lifelong learning processes (1997, p. 220).

Since that time the concept has become increasingly contested as new technologies and new applications for technology have emerged, many of which have been spawned by progressively ubiquitous access to the internet, and the proliferation of personal, mobile digital devices. Terms such as 'information literacy' (Zurkowski 1974), 'computer literacy’ (Tsai 2002), 'internet literacy' (Harrison 2017), 'media literacy’ (Christ and Potter 1998) and recently, 'multi-modal literacy' (Heydon 2007) have all been associated with effective use of digital resources in teaching and learning, and have been promoted as components of an inclusive view of digital literacy (Grusczynska and Pountney 2013). As Helsper (2008) identifies, reaching a singular definition of digital literacy is challenging, due to constantly evolving technological, cultural and societal 
landscapes redefining what, when and how digital technologies are used in personal and professional activities.

In terms of teacher education, producing digitally-literate students has generally meant the prioritisation of technical skills in using digital tools and systems deemed appropriate to educational settings, and identifying how these can be used within particular units of learning (Admiraal et al. 2016). This approach assumes that doing this, "equips preservice teachers with a set of basic competencies they can transfer to their future classroom practice" (Admiraal et al. 2016, p. 106). However, these approaches have been criticised for their narrow skills focus, lack of authenticity, failure to take account of different sociocultural contexts for technology use, and their ineffective, reductive design (Gruszczynska et al. 2013; Lim et al. 2011; Lund et al. 2014; Ottestad et al. 2014). Others have identified limitations in their overly technical approach that ignores wider considerations, including ethical, digital citizenship, health, wellbeing, safety and social/collaborative elements (Foulger et al. 2017; Hinrichsen and Coombs 2013). More recent studies have called for a reconceptualisation of the outcomes of teacher education programmes, suggesting the present skills-focused digital literacy emphasis be abandoned, in favour of broader digital competency models that recognise the more diverse knowledge, capabilities and dispositions needed by future teachers.

In considering the nature of general digital competence, Janssen et al. comment that:

...digital competency clearly involves more than knowing how to use devices and applications... which is intricately connected with skills to communicate with ICT, as well as information skills. Sensible and healthy use of ICT requires particular knowledge and attitudes regarding legal and ethical aspects, privacy and security, as well as understanding the role of ICT in society and a balanced attitude towards technology... (Janssen et al. 2013, p. 480).

While this conceptualisation acknowledges the relevance and importance of technical knowledge and skills, it adopts a wider socio-cultural stance by signalling the need to understand and consider broader implications and effects of digital technologies on individuals and society. It also introduces dispositional and attitudinal elements-or what Janssen et al. (2013) terms developing a "mind-set" (p. 474) towards technological innovations, in an effort to better understand and critically appraise their role and influence in forming new practices. This represents a considerable challenge for teacher educators, who not only need to better support their students to more effectively utilise digital resources in their future classrooms, but must also help them understand and develop a concern for broader considerations around technology use, and its impacts. Additionally, the notion of competence implies a need for constant revision, reflecting changes to technological systems and uses that, "take into account the evolving nature of technologies" (Janssen et al. 2013, p. 474). This requires teacher educators to constantly reflect on current capabilities and needs and where necessary access professional learning, responding to rapidly changing educational environments and opportunities afforded by emerging technology innovations.

\section{Existing frameworks guiding teacher digital capability development}

Supporting development of the teacher digital competency framework introduced in this article, a scoping review of literature was undertaken investigating the characteristics of some present frameworks commonly used in teacher education. The purpose of the review 
was not to develop a definitive summary encompassing all frameworks. Instead, it overviewed frameworks that had been developed specifically for teacher education, made reference to possible application in teacher education, or had been researched and reported on within teacher education contexts, to identify the extent to which they represented a holistic interpretation of digital competence as described by Janssen et al. (2013). To facilitate this, a multi-database search was completed using various combinations of the keywords: teacher, education, teaching, digital, literacy, skills, competencies, ICT, technology, capabilities, information. From the results, a selection of frequently occurring frameworks considered most aligned with teacher education were selected for analysis (i.e., ones conceptualised, implemented or researched in teacher education contexts). A summary of these is presented in "Appendix". In interpreting the table, different sized black circles have been used to indicate the level of emphasis given in each framework to skills development (S), pedagogical (P) and curriculum (C) changes, dispositional/attitudinal factors (Disp.) and personal considerations (Pers.). These are further defined in the notes section at the bottom of the table.

As indicated in the table there is a solid emphasis in most frameworks on skills development, although only TPACK, the UNESCO framework and to a lesser extent the ISTE standards, explicitly linked these to associated changes in pedagogy and curriculum. Skills generally focused on technical/operational aspects of ICT and information skills-specifically how to use devices and software to access, work with and evaluate information for a range of curriculum and teaching purposes, and the type of thinking associated with this (e.g., analysis, evaluation, critical). The frameworks were also quite different in structure, with the ISTE standards, UNESCO competencies and ICTE-MM maturity model adopting universal 'checklist' formats, while the others were more conceptual (broader ideas informing bespoke development). Notably, no existing frameworks included more than a passing mention of personal dispositions/attitudes or understandings of wider issues or safety and wellbeing (etc.) considerations, as components of teacher education students' digital competence.

Two conceptual frameworks were indicated in literature as frequently used for informing the design of teacher education digital capability programmes, and were well-supported by empirical research. They were Mishra and Koehler's (2006) TPACK framework (e.g., Graziano et al. 2017; Kimmons and Hall 2018; Krause and Lynch 2016; Reyes et al. 2017; Tan et al. 2019; Voogt and McKenney 2017) and Puentedura's (2006) SAMR model (e.g., Aldosemani 2019; Baz et al. 2018; Beisel 2017; Kihoza et al. 2016; Sardone 2019). The next section investigates these frameworks in more detail, evaluating each for their capacity to support teacher educators in their efforts to foster broadly-based digital competence in their students.

SAMR (substitution, augmentation, modification, redefinition) is essentially a descriptive framework that maps different educational uses of technology hierarchically against levels or stages-progressing from Substitution ('doing digitally' what has traditionally been carried out using conventional resources) through to Redefinition (curriculum, pedagogy and practice reconceptualised through digital technologies). SAMR has been widely adopted by teacher educators and schools as a pragmatic guide for signposting ICT development progress, as they work towards what is seen as the utopian position of curriculum Redefinition through technology (Geer et al. 2017; Hilton 2016). According to Puentedura (2006), at the Redefinition stage, "technology allows for the creation of new tasks, previously inconceivable" (slide 3)-tasks, he claims, that align with the exercise of higher order thinking capabilities such as analysing, evaluating and creating. At the Substitution stage, "technology acts as a direct tool substitute with no functional change" (slide 3), 
which Puentedura (2006) aligns with lower order thinking capabilities, such as understanding and remembering. The Augmentation and Modification stages represent intermediate steps between Substitution and Redefinition, describing increasing complexity and sophistication in using technology to facilitate changes to learning design and pedagogy, progressively supporting greater levels of curriculum innovation (Fig. 1).

While the SAMR framework may be useful for pre-service and practicing teachers by providing descriptive 'aim points' towards which to evolve their practice, it does not provide concrete illustrations of the sort of practices that might represent each stage, or ways of transitioning through the stages - nor does it explicitly account for supporting and necessary pedagogical, technological and learning design changes. Although appealing possibly because of its simplicity, SAMR focuses solely on describing levels of subject-based technology integration, reflecting a narrow interpretation of the understandings teacher education students need for the more holistic and comprehensive capability set required by an expanded view of digital competence.

A broader and more inclusive framework that goes some way towards addressing the shortcomings of SAMR, is Mishra and Koehler's (2006) technological pedagogical content knowledge, or TPACK model. TPACK builds on the earlier work of Shulman (1986), "to explain how teachers' understanding of educational technologies and pedagogical content knowledge (PCK) interact with one another to produce effective teaching with technology" (Koehler et al. 2013, p. 14). Unlike SAMR, TPACK does not represent a hierarchy or staged progression, but rather presents a holistic model that theorises the relationship between, and contribution of, technological, pedagogical and content knowledge to effective curriculum learning-focused technology use. TPACK merges each element into a central core that blends deep and robust discipline conceptual knowledge (CK) with an understanding of the potential of, and capacity to use technology (TCK) to enhance learning, through supportive pedagogies (TPK) that acknowledge students' prior understandings and learning needs (Fig. 2).

The success of TPACK relies on the capabilities of teachers within each domain, and their capacity for flexibility, willingness to update, and readiness to explore how the

Fig. 1 The SAMR model (from Puentedura 2006)

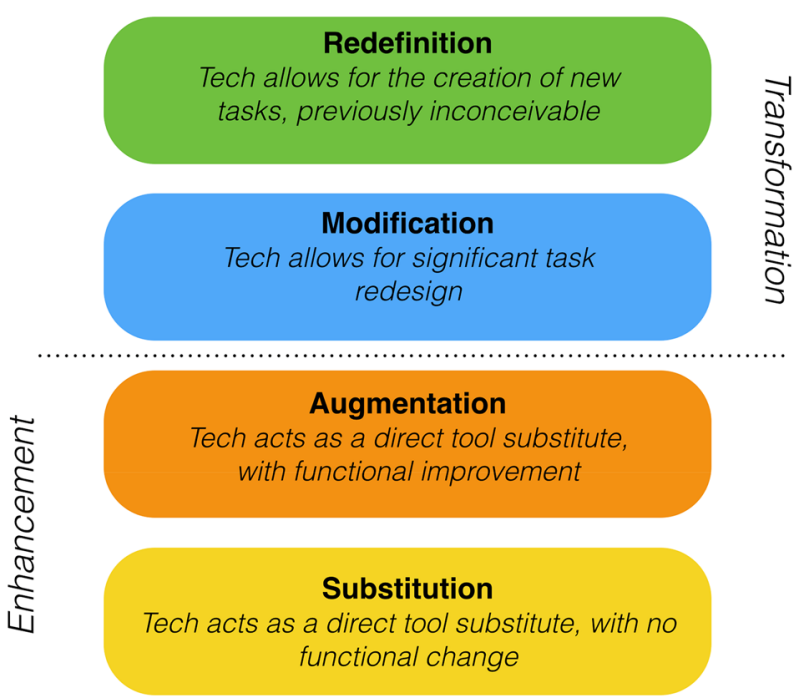


Fig. 2 The TPACK framework (from Mishra and Koehler 2006)

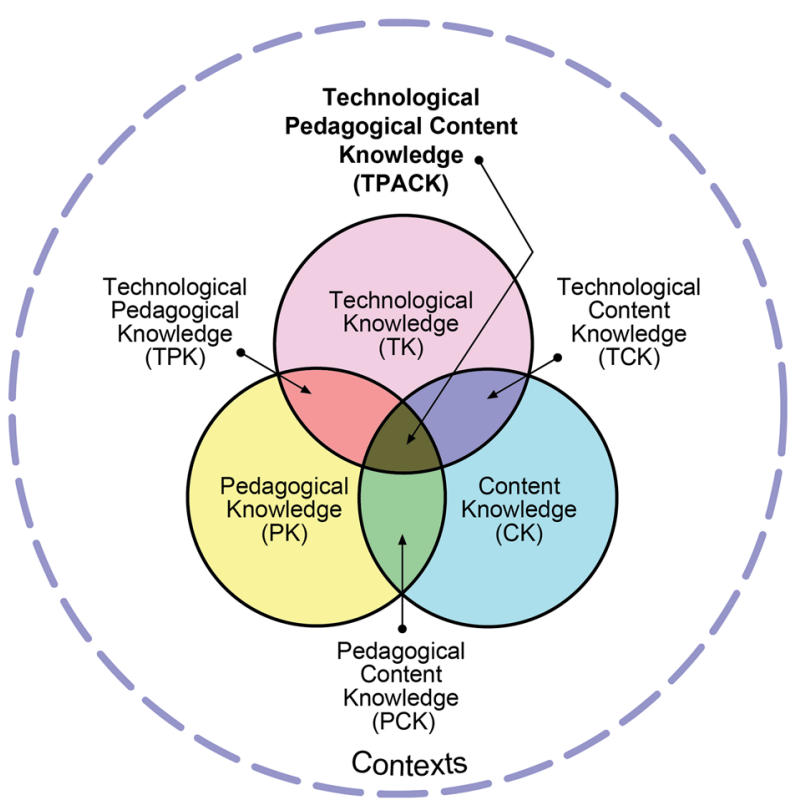

domains interrelate to support effective technology use in a range of different situations (Harris et al. 2009). While TPACK acknowledges the integrative relationship between conceptual content knowledge and pedagogy and technology, within teacher education programmes this relationship is seldom reflected in course design and teaching practices (Ndongfack 2015). According to Ndongfack, fundamental structural issues exist in many teacher education programmes that work against building integrative TPACK knowledge. These include a tendency to, "focus on developing knowledge of pedagogy and content separately... and empowering them (students) with some basic computer skills, not how to integrate them into the teaching and learning process" (Ndongfack 2015, p. 1707). This separation is also noted in some frameworks that list capabilities separately, rather than indicating how they work together in more effective, integrative approaches (e.g., ISTE 2017; UNESCO 2011). Despite the emergence of a few studies signalling discipline-related learning benefits from redeveloping courses using an integrative TPACK approach (e.g., Habowski and Mouza 2014), such innovations are presently not commonplace in teacher education programmes.

Although offering a more comprehensive framework that acknowledges the complexities of optimising digital technology's contribution in the classroom, TPACK maintains the focus of other frameworks firmly on subject learning-related outcomes. That is, it theorises the relationship between, and blending of pedagogical, content and technological knowledge to enhance the learning performance of students in, and sometimes across, subject disciplines. While valuable for this purpose, TPACK in its original form is limited in its usefulness for building a broader-based conceptualisation of teacher digital competence.

Since TPACK's publication in 2006, the educational and technological landscape has altered significantly, largely in response to new digital innovations and rapidly changing and often unstable social, political and economic environments. Given these changes, it could be argued that the knowledge school students will need and that their teachers will need to teach them, to safely, sustainably and productively engage with and leverage 
benefits from digital resources in challenging future environments, requires more than simple 'technical' exposure to ICT in traditional school subjects. Concerns that were not apparent even 10 years ago, have emerged as major players in our understanding of what it now means to be 'digitally competent'. These include considerations such as cybersafety and managing personal data and online presence, digital citizenship, ethics and judgement, and building knowledge from, and collaborating in, online networks and virtual environments. A more holistic conceptual framework is needed that takes account of such factors, and teacher educators must widen their focus to ensure their students understand and are equipped to teach these, when they begin their careers.

\section{Understanding digital competence}

Janssen et al.'s (2013) Delphi study provides insights into what a more holistic digital competence framework might look like. Their survey of 95 experts comprising representatives from academic, education and training, government and policy and IT business sectors, revealed twelve elements considered essential to broadly-based digital competence. These are summarised in Table 1.

Janssen et al. (2013) conceptualised each element as a 'building block' in establishing holistic digital competence. They organised these into a model that displayed how the elements worked together, resulting in, "seamless use demonstrating self-efficacy" (p. 478) (Fig. 3). Central to the model are 'core' competencies that include functional, integrative and specialised uses of digital technology, that are enhanced by improved capabilities in

Table 1 An explanation of Janssen et al.'s (2013) areas of digital competence

\begin{tabular}{|c|c|}
\hline Competency & Knowledge and understanding of \\
\hline Functional & terminology, use of digital technologies for basic purposes \\
\hline Integrative & effective integration of digital technologies into everyday life \\
\hline Specialised & optimising digital technology use for work and creative purposes \\
\hline Communication and collaboration & $\begin{array}{l}\text { digitally-supported networking for collaborative knowledge develop- } \\
\text { ment }\end{array}$ \\
\hline Information management & $\begin{array}{l}\text { using digital technologies to access, organise, analyse and judge the } \\
\text { relevance and accuracy of digital informatio }\end{array}$ \\
\hline Privacy and security & measures to protect one's personal identity, data, and security \\
\hline Legal and ethical & $\begin{array}{l}\text { socially appropriate behaviours in digital environments, including } \\
\text { legal and ethical factors associated with the use of digital technolo- } \\
\text { gies and content }\end{array}$ \\
\hline Technology and society & $\begin{array}{l}\text { the context and use of digital technologies, and the impacts of these } \\
\text { on people and society }\end{array}$ \\
\hline Learning with and about technology & $\begin{array}{l}\text { emerging digital technologies, and how they can be used to support } \\
\text { learning across the lifespan }\end{array}$ \\
\hline Informed decision making & critical selection of digital technologies suited to needs and purpose \\
\hline Coherence/self-efficacy & $\begin{array}{l}\text { using digital technologies to improve personal and professional } \\
\text { performance }\end{array}$ \\
\hline Dispositional & $\begin{array}{l}\text { the importance of maintaining an objective and balanced perspective } \\
\text { on digital innovations, and being confident to explore and exploit } \\
\text { their potential as opportunities arise }\end{array}$ \\
\hline
\end{tabular}


Fig. 3 Janssen et al.'s (2013) elements of digital competence model

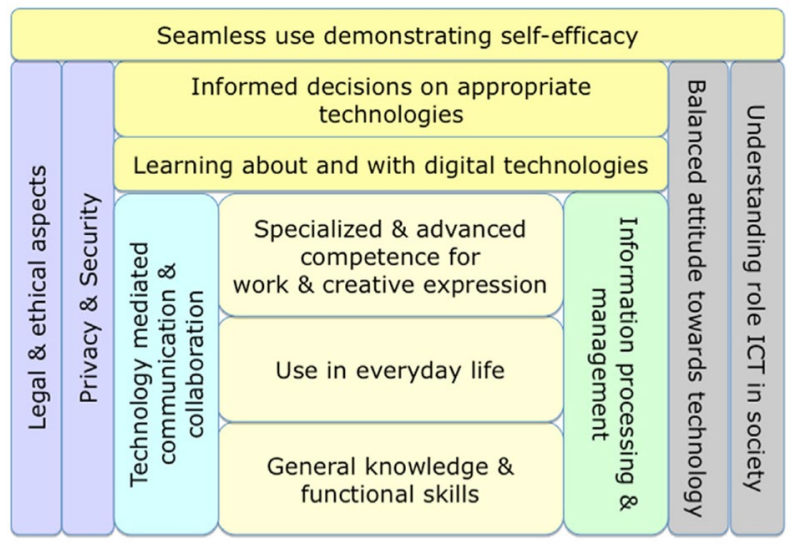

networking (technology-mediated communication and collaboration) and information management (accessing and using digital information). Running parallel to these are what they term 'supportive' competencies. These are indicated in Fig. 3 by the purple and grey vertical pillars. They represent competencies including understanding legal and ethical considerations, personal and societal impacts and effects, and dispositional elements such as maintaining a balanced and objective attitude towards technology innovation, and a willingness to explore the potential of emerging technologies for personal and professional benefit. As competence develops, personal reflection and increased levels of integration into all aspects of daily activity contribute to greater awareness of how appropriate digital technology use can be leveraged across the lifespan, leading to seamless personal and professionally-beneficial selection and use.

In their discussion of the model, Janssen et al. (2013) signal limitations to its direct application to specific contexts. They point to the balance that needs to be struck between choosing, "a common denominator that is broad enough to encompass nearly everything, (thereby) being over-inclusive or too vague, or a narrower common denominator (with the risk of) the conception being too restrictive" (p. 480). They further comment that, "digital competence should be understood as a pluralistic concept" (p. 480), emphasising that consideration must be given to the unique but interrelated and connected purposes and functions of digital technology, in different contexts. Janssen et al. (2013) highlight that the way in which digital competence is developed and displayed in one context will differ from others, and that it is important to view digital competence, "from a plurality of angles" (p. 480).

In relation to teacher education, Lund et al. (2014) comment on the unique challenges faced by teacher educators in developing a holistic view of digital competence in their students. They point out that teacher educators are required both to educate their students about using present and emerging digital resources in their own professional practice, but also about how to make their students, "capable of using technology in productive ways" (p. 286). Achieving this is particularly difficult, as it requires catering for more than the immediate capability needs of students, to build a transformative competence, that will enable them to interpret into specific instructive, learning design, classroom organisation and assessment practices, how to best use digital resources to support their own students' learning (Lund et al. 2014). 
Other studies highlight the need for teacher educators and their students to consider digital technologies as culturally-embedded artefacts, understanding how they shape and influence our knowledge construction, social interactions and development as people (e.g., Ludvigsen and Mørch 2010; Säljö 2010). Säljö (2010) suggests that in assessing the impact of digital technology on learning, we need to broaden our perspective to consider not only knowledge outcomes, but also how these outcomes were arrived at, through using digital artefacts. He terms this "performative action" (Säljö 2010, p. 60), arguing that it is the basis for transforming our understanding of what learning is, what we should expect people to learn, and how this learning can occur. Building on Säljö's work, Lund et al. (2014) argues the importance of performative competence in supporting teacher education students to identify transformative uses for technology in teaching. Noting their unique position as newcomers to school environments, Lund et al. suggest performative competence will enable beginning teachers to resist, "merely being socialised into existing practices, but being able to contribute to the development of new ones" (2014, p. 287). While acknowledging difficulties achieving this in practice, Lund et al. view performative competence as essential to a broad understanding of teacher digital competence in a knowledge-based society.

\section{The contested nature of teacher digital competence}

To this point, reviewed literature has presented different perspectives on building teacher education students' digital capability. Models such as TPACK and SAMR represent pragmatic approaches, suggesting capability comprises the capacity to effectively combine technological, pedagogical and content-knowledge to use digital resources to enhance subject knowledge outcomes. Other discussion signals a broader interpretation, including elements such as personal 'digital dispositions' and behaviours, and consideration of the impacts of digital technologies on people, society and environment (e.g., Janssen et al. 2013). Some suggest incompatibility exists between these two interpretations, "with tensions between understandings as a skill set and technical competence, and those that focus on socio-cultural and communicative practices" (Gruszczynska and Pountney 2013, p. 29); while others point to their compatibility and complementary nature (e.g., Ottestad et al. 2014; Põldoja et al. 2011).

Official documents and frameworks tend to emphasise ICT skills or 'information literacy' perspectives, prioritising the acquisition of technical and procedural skills that can be planned for and assessed against professional standards (e.g., Australia's National Professional Standards for Teachers; ISTE Standards for Educators; UNESCO ICT Competency Standards for Teachers). On the other hand, researchers and academics are calling for a broadening of the emphasis to encompass personal and socio-cultural factors, such as managing one's personal information and online profile, safety and security, and exercising digital judgement (e.g., Foulger et al. 2017; Salas-Pilco 2013). From a policy standpoint, the reductive approach of standards frameworks holds considerable appeal, due to the relative simplicity of assessing capabilities through testing or checklist-like recording. However, developing and assessing non-technical personal competencies is far more difficult although arguably just as important, given the need to educate students about dangers such as cyberbullying and online predatory behaviours through social media, identity theft, and the misuse of digitally-harvested personal information (Palermiti et al. 2017; Richards et al. 2015). 
It is apparent considerable debate exists in literature concerning the exact definition and nature of teacher digital 'competence', and how this can be best developed during initial teacher education. While prevailing framework emphases based on digital literacy notions of technical, pedagogical and content knowledge go some way towards informing the capabilities required by graduating teachers, it is argued that these are insufficient in present and future educational environments. School students need to know more than procedural and technical skills and benefit from digital technology's use in curriculum subject learning. It could reasonably be expected that teacher education students should strive to extend their competence beyond didactic application of digital technologies, towards a more holistic view encompassing personal and societal considerations, such as those introduced earlier. While this is a challenging undertaking it is a vitally important one, if the students they teach are to be better-prepared to function productively and safely in increasingly digitallymediated personal and professional environments.

\section{Conceptual frameworks and digital competence}

Antonenko (2014) describes conceptual frameworks as, "practical tools-a process and a product for organising and aligning all aspects of an inquiry" (p. 55). According to Antoneko, conceptual frameworks can take different forms for different purposes, but generally communicate, "the system of beliefs, assumptions, theories and concepts that support and inform (inquiry)" (2014, p. 55). Ravitch and Riggan (2012) suggest conceptual frameworks define the 'big ideas' associated with a particular inquiry, and comprise a blend of personal beliefs, assumptions and experiential knowledge; topical research (knowledge relevant to the field of study), and theories generated from prior empirical work. While conceptual frameworks are important for defining the key ideas, relevance, rationale and foci for an inquiry or programme, they are not intended to act as a 'formula' or 'prescription' detailing, in this case, universally-applicable curricula with the goal of improving students' digital capabilities. The purpose of a conceptual framework is to guide and inform curriculum and programme design and content which is tailored by expert professionals to the context in which it is to function, not specify precisely what it should comprise or how it should be delivered. The next section introduces a teacher digital competence (TDC) conceptual framework that builds on Janssen et al.'s (2013) work. It positions Janssen et al.'s general competencies within the context of teacher education, extending it by introducing 'teaching specific' competencies aligned with TPACK, and integrated, personal/ethical and personal/professional competencies.

\section{The teacher digital competence (TDC) framework}

As signalled by Lund et al. (2014), the transformative potential of teachers new to the classroom offering contemporary ideas and perspectives, needs to be realised before they become enculturated or socialised into existing school norms and practices. By encouraging them to consider an expanded view of teacher digital competence, that includes but moves beyond the present focus on didactic application and technically-oriented digital literacy-building before entering the classroom, there exists the possibility that they challenge existing thinking, possibly becoming 'change agents' towards a more inclusive and contemporary understanding of teacher digital competence. At a practical level, such 
understandings will also support them in their efforts to plan and structure learning programmes to foster relevant competencies in their own students. The following section introduces elements of a comprehensive framework that depicts the integration of curriculum-related and personal-ethical and personal-professional competencies, argued above as essential for establishing the broad capability set required of teachers currently entering the profession, and in the future.

\section{Understanding the framework}

The TDC framework (Fig. 4) represents diagrammatically a broadly-based conceptualisation of teacher digital competence. While the framework could equally be used to inform the competency set of practicing teachers, the discussion that follows and suggestions for use, specifically focus on its applicability to teacher education.

\section{Curriculum competencies}

The TDC framework extends TPACK-aligned competencies that specifically focus on the skills and capabilities needed to integrate digital resources to support subject learning. The green horizontal bars depict the main elements of TPACK, with the vertical, dark blue side pillars indicating their integrated nature in forming the capabilities and skills needed to use digital technologies for subject-based learning. Technical competence refers to robust knowledge of the 'mechanics' of operating various digital technologies, such as mobile devices, apps, network services and so on. Technological competence focuses more on theoretical understandings related to the role and potential of digital technologies in teaching

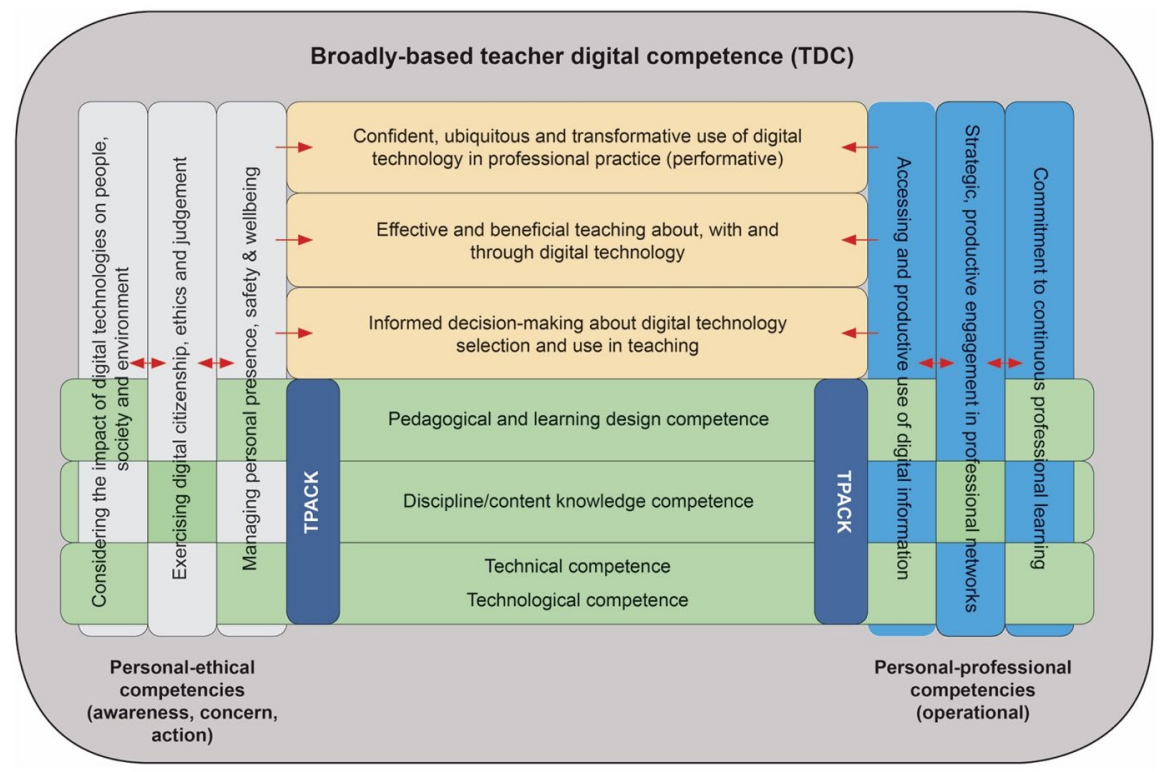

Fig. 4 The teacher digital competence (TDC) framework 
and learning, and knowledge of the rationale underpinning its inclusion in educational environments. In short, this competence emphasises understanding the hows (technical) and whys (technological) of digital technology in the classroom.

Discipline and content knowledge competence aligns closely with Mishra and Koehler's (2006) definition, that is, knowledge of, "the actual subject matter to be learned and taught" (p. 1025). Although possibly self-evident, teacher education students need sound conceptual knowledge of subject content in order to teach it, with or without the assistance of technology. Put simply, they must 'know their stuff'. The third bar, pedagogical and learning design competence, refers to the need for robust knowledge of how to plan and teach with, through and about digital technologies. Pedagogy has been described as, "the science and art of teaching" (Battro et al. 2013, p. 177), suggesting a blending of technical and organisational capabilities with personal teaching creativity, flair and style. Competence in this element requires students to know how to best teach with, about and through digital technologies, focusing on effective and engaging teaching performance, strategies, resource, class management and organisational approaches, and appropriate learning designs. These might include knowledge of effective class group and resource access systems, critical review and selection of different technologies and applications as being 'fit for purpose', the compatibility of digital resources with subject and problem, project and inquiry-based learning designs, and so on. The three core competencies integrate to establish a solid foundation upon which teacher education students are able to make informed and beneficial decisions about digital resource use, improve their teaching effectiveness with them, and develop confident and seamless digitally-enhanced teaching practice (the yellow bars).

\section{Personal-ethical competencies}

Flanking the core competencies, the framework introduces two new sets of integrated competencies: personal-ethical and personal-professional. Personal-ethical competencies require teacher education students to understand, model and where relevant, include specific teaching content, to assist their students to access and use digital resources in a sustainable, safe and ethical way. Broadly, the first two pillars target what it means to be a good 'digital citizen', and aim to build knowledge of how to maintain personal safety and data security in a range of digitally-mediated environments (e.g., social networks), and ensure health and wellbeing while using devices. These respond to issues such as the increasing instances of identity theft, predatory online behaviours, cyberbullying, and harvesting and misuse of personal information; and also physical and psychological problems that have been associated with device overreliance and use, such as obesity, internet and game addiction, and social isolation. In practical terms, these two pillars serve the dual function of educating about the implications and effects of digital transactions and interactions on others, and also teaching students specific mitigation strategies, should they fall victim to negative digitally-mediated behaviours. The third pillar considers the impacts of digital technologies on people, society and environment. This has been included responding to increasing global concerns such as multinational company exploitation of workers in device production factories and at raw material source sites, the dumping of discarded devices in toxic waste pits in developing countries, and the intrusive effects digital devices can have on maintaining a sustainable and healthy work/life balance. The pillar encourages students to take a critical perspective on digital technologies, questioning who the winners 
and losers are from technological innovation, and adopting a proactive personal stance on societal issues related to the effects of technologies.

It should be noted that the order of the pillars does not represent their level of importance, and the red double-headed arrows indicate their interrelated nature. For example, it could be argued that the centre pillar, exercising ethical digital citizenship and judgement, broadly encompasses competencies included in the other two. While acknowledging this may be the case, to enhance the framework's usefulness as a practical tool for informing teacher educators' planning and practice, they have been detailed separately.

\section{Personal-professional competencies}

On the right flank of the core competencies, the lighter blue pillars depict three, integrated personal-professional competencies. The first of these encompasses capabilities aligned with earlier conceptualisations of information literacy. This includes skills such as recognising the need for information, sourcing relevant information using effective search strategies (digital and non-digital forms), evaluating and organising information, integrating information for practical application, and critical thinking and problem solving (Webber and Johnston 2000). This pillar effectively represents an operational competence, that will support students across all activities associated with the use of digital resources for information access, exchange and application.

The second pillar, strategic, productive engagement in professional networks, reflects the importance of understanding how best to leverage personal and professional benefit from strategic participation in an ever-expanding array of online networks and collaborative environments. However, competence in this element must focus on strategic engagement - that is, selection and collaborative participation likely to lead to professional benefit for the individual, and the online community as a whole. The web is abundant with teaching-related networks and communities, notwithstanding more generic professional networks such as LinkedIn or Xing. It is simply not possible, nor desirable, to engage in them all. Teacher education students must understand the importance of strategic engagement to ensure time and effort spent professional networking is beneficial and productive.

The first two personal-professional pillars are closely related. Well-developed information literacy capabilities are essential for assessing the value and worth of participating in online environments and communities, such as professional networks. They are important for evaluating the quality and accuracy of information communicated and shared within them, and for determining the usefulness of this information for furthering professional knowledge and practice. While information literacy integrates tightly with core curriculum-focused competencies, it also extends beyond these to personal-professional functions involving interaction and activity beyond the classroom.

The third pillar, commitment to continuous professional learning, is both a dispositional and a functional competency. It addresses the willingness of new teachers entering the profession to commit to a programme of ongoing professional learning, responding to new opportunities presented by emerging technology innovations. Dispositionally, this competency describes a positive mindset (Amirault 2015) that fosters an attitude that supports investigation and testing the potential of new technologies to enhance core and personalprofessional competencies. At a functional level, this disposition motivates continuous engagement in professional learning to build the knowledge needed to realise the potential offered by the innovation. Maintaining competence in this pillar is ongoing and iterative in nature, reflecting understanding that technology innovation is not static, but that new 
possibilities for using digital resources in teaching and for other professional activities, are continually emerging. As for personal-ethical competence, personal-professional competencies work together rather than in isolation. Dispositions and capabilities aligned with one pillar, support development in the others. In Fig. 4, this interaction is indicated by the double-headed arrows.

\section{The integration of personal-ethical and personal-professional competencies}

Figure 4 shows the weaving of personal-ethical and personal-professional competencies with the core TPACK-aligned competencies. This signals the importance of teacher education students understanding how to integrate into subject-related activities involving learning with, about and through digital technologies, understandings and capabilities aligned with personal-ethical and personal-professional competencies. This integration could occur at planning, pedagogical and practice levels. That is, students should be encouraged to identify where, across all subjects and the full array of school activity, opportunities might exist to build their students' knowledge, skills and dispositions defined by the integrated pillars. These opportunities could reside in planned learning experiences where digital resources are directly used to support subject or discipline-specific knowledge outcomesfor example, using dissection simulations in biology before evaluating their advantages and disadvantages.

Equally, they might be embedded in experiences where the focus is on other learningfor example, planning and teaching a series of lessons investigating the physical and psychological impacts of game addiction on teenagers, as part of the health and wellbeing curriculum. At primary school level, opportunities might be present in literacy lessons, where reading content could introduce scenarios about western countries' e-waste dumping, and the impact this has on the people and environment of destination African nations. Apart from deliberately planned experiences, opportunities might also be present at an incidental, pedagogical level. These could occur as 'teachable moments' within normal classroom programmes, and teacher education students should be encouraged to identify and capitalise upon them when they arise, as they hone their skills during school placements and practicums.

\section{Using the framework}

Ideally, building broadly-based digital competence within teacher education programmes requires the engagement of all faculty and an interdisciplinary approach. Opportunities to develop the competencies inherent in the pillars of the framework should not be viewed as the sole responsibility or within the skill set of only one or two teacher educators. Successful implementation requires the participation of all teaching faculty, who must have a consistent understanding of the breadth and definition of the competencies. In a perfect world faculty would adopt a coordinated, interdisciplinary approach to the delivery of teacher education programmes, rather than the siloed, discipline-based models that currently prevail. As noted by Habowski and Mouza (2014), interdisciplinary approaches to teacher education can significantly enhance student learning, and would provide a unified and coordinated foundation for delivering the framework's goals. 
However, the reality is that interdisciplinary approaches are not commonplace, and the rigid, subject-based structures of universities where most teacher education occurs, are exceedingly difficult to change. Notwithstanding this, the TDC framework could be used to map or audit the content and pedagogy of existing or new teacher education courses across discipline areas, to examine the extent to which they offer opportunities for students to build more holistic understandings and capabilities aligned with the framework. This does not necessarily mean adopting an interdisciplinary approach to planning and teaching, but could take the form of staff from separate departments working with the framework to identify which components of it could be delivered or incorporated into discipline coursework. For example, health education faculty may find opportunities to effectively integrate personal-ethical (wellbeing/safety) competencies in units by requiring students to research and report on latest studies on the physical and psychological effects of prolonged device use, while courses in science education might better align with personal-professional competencies such as access and productive use of information, through, amongst other means, engaging in scientific networks. Courses in special or inclusive education in units focused on educational equity, might include content to learn how and why digital technologies can and should be used to assist students with special learning needs. Similarly, social science education curricula may include components that focus on building personal-ethical competence (impacts on people, society, environment), through analysis of supply chain practices and processes used in the production and disposal of digital devices. However, to support such approaches, the TDC framework must be well understood and accepted by all faculty, who must be willing to apply it when planning and developing their programs. Ideally, the framework could form the focal point for education faculty or department professional development, with staff identifying and committing to implementing relevant elements, where opportunities exist.

Due to its comprehensive nature, it is important that a collaborative approach is taken to implementing the framework. At a qualification level, this may mean directors working with senior faculty to identify and integrate TDC elements across a degree (e.g., early childhood, elementary, secondary), or at a program level, convenors and teaching staff planning and implementing within specific disciplines (e.g., literacy, science, numeracy). Targeted TDC elements should be made explicit to students via course outlines, integrated into course content, and reflected or directly embedded in assessment tasks. Implementation must include faculty modelling the sort of pedagogy, learning content and attitudes and behaviours, inherent in the framework. This is particularly important, given the expectation that their students will also model these in their own classes, when they begin their careers. Whichever approach is adopted, it is vital that efforts are made to move beyond the current technical/procedural emphasis, thereby better-equipping graduating teachers with an understanding of the breadth of their responsibilities for educating their students to function safely, ethically and productively, in increasingly digital environments.

\section{Conclusion}

This article argues the need to expand teacher education students' understanding of the sort of competencies required to function productively, safely and ethically in diverse and increasingly digitally-mediated environments. It highlights the importance of this in relation to their future classroom roles, educating young people to help them build capacity to leverage advantage from digital resources and information in safe, secure and sustainable 
ways. To facilitate this, a broadly-based teacher digital competence framework is introduced, which teacher educators have an important part to play in implementing through modelling and deliberate planning and teaching. It further suggests that implementing the framework is the responsibility of all faculty, who need to have consistent and well-developed knowledge of its intent, scope and content. It is hoped the TDC framework can provide a focal point for policy revision and faculty discussion, planning and action, that will lead to improvement in the preparation of graduating teachers for our future classrooms.

Funding No funding was received supporting this study.

\section{Compliance with ethical standards}

Conflict of interest The author certifies he has no conflict of interest influencing this study.

Ethical approval Ethical clearance was not a requirement of this study.

Open Access This article is licensed under a Creative Commons Attribution 4.0 International License, which permits use, sharing, adaptation, distribution and reproduction in any medium or format, as long as you give appropriate credit to the original author(s) and the source, provide a link to the Creative Commons licence, and indicate if changes were made. The images or other third party material in this article are included in the article's Creative Commons licence, unless indicated otherwise in a credit line to the material. If material is not included in the article's Creative Commons licence and your intended use is not permitted by statutory regulation or exceeds the permitted use, you will need to obtain permission directly from the copyright holder. To view a copy of this licence, visit http://creativecommons.org/licenses/by/4.0/. 


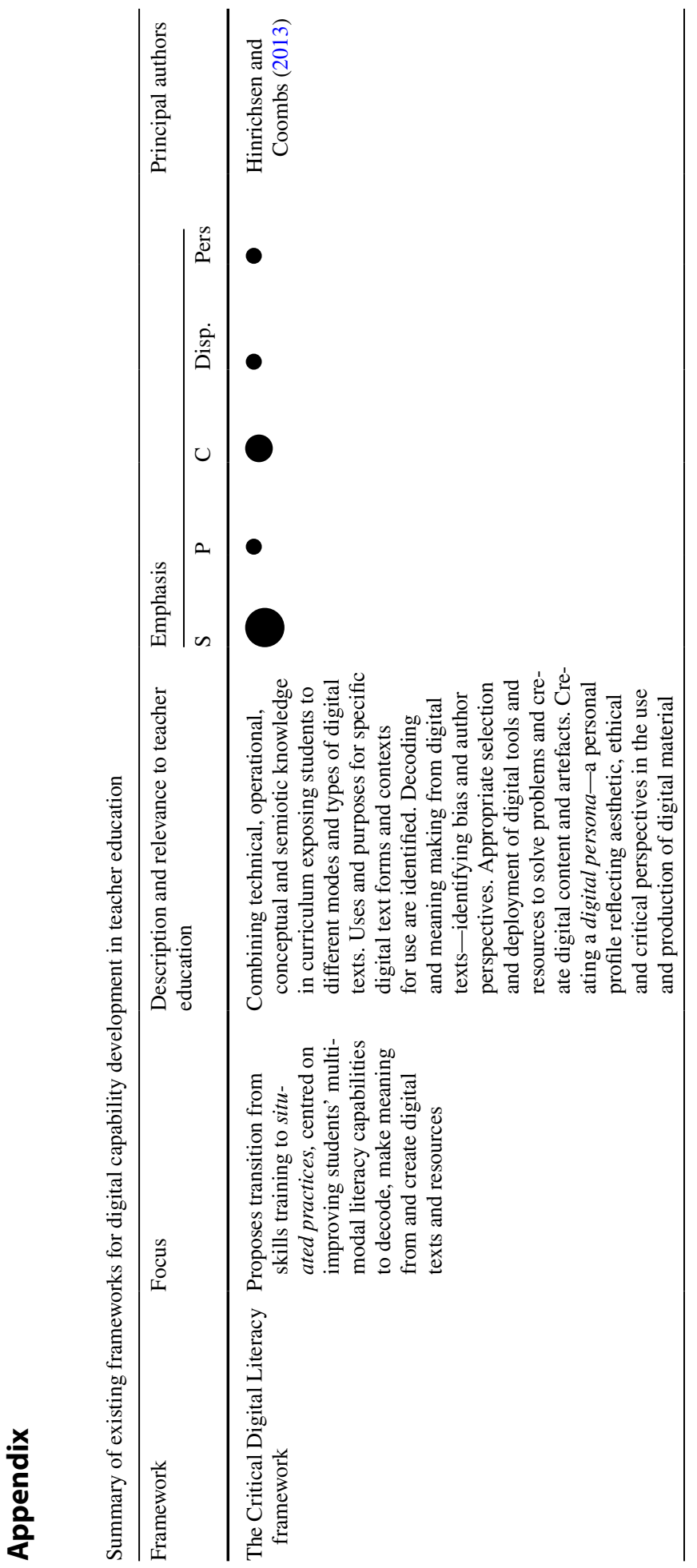




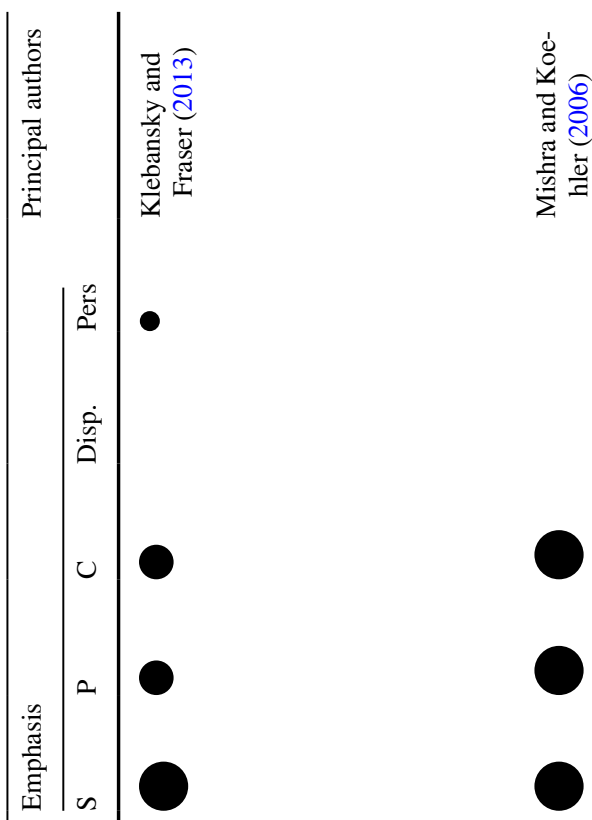

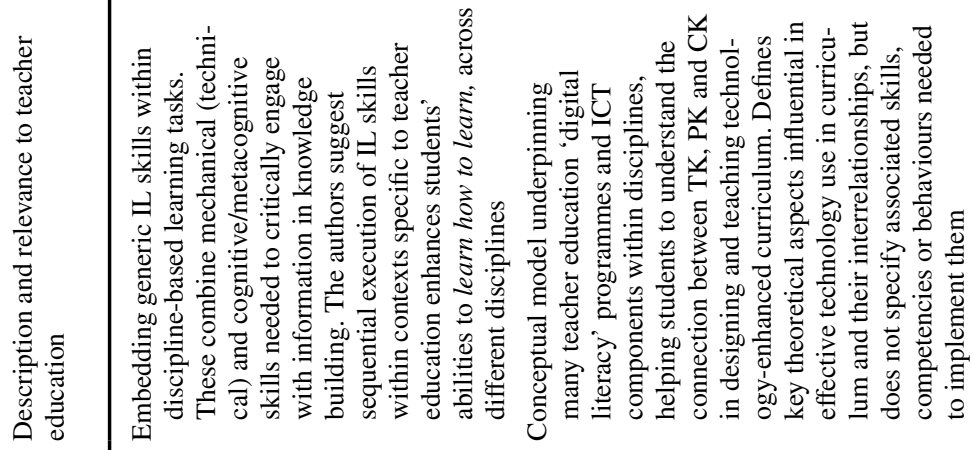

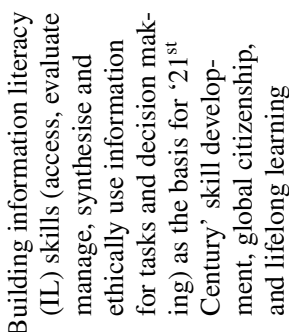

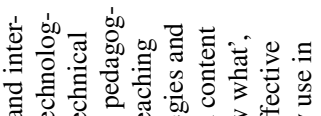

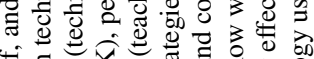

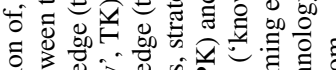

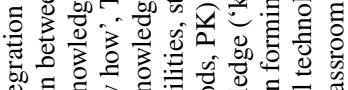

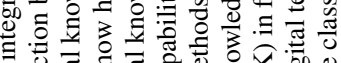

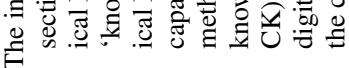

苔

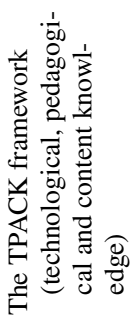




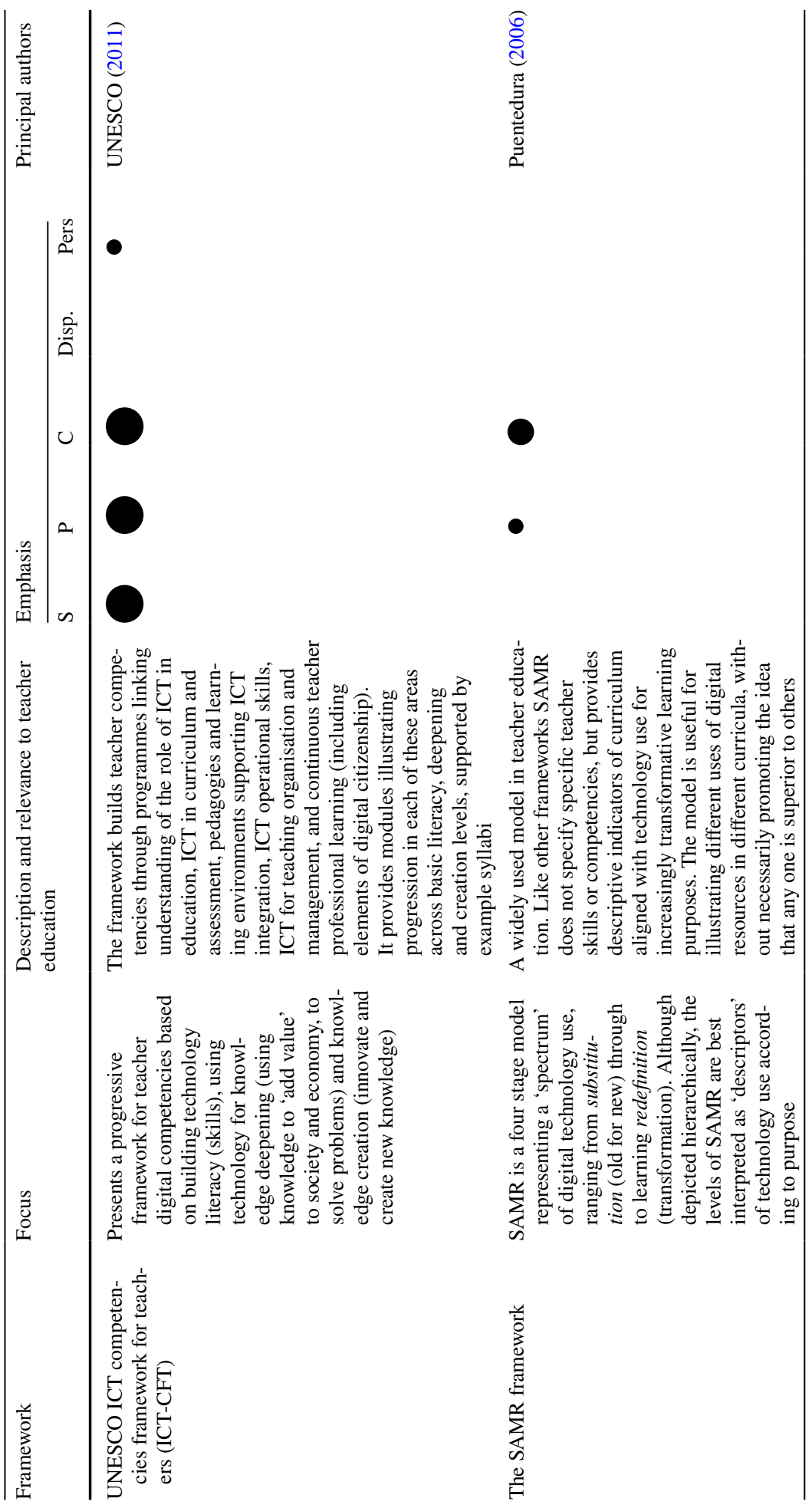




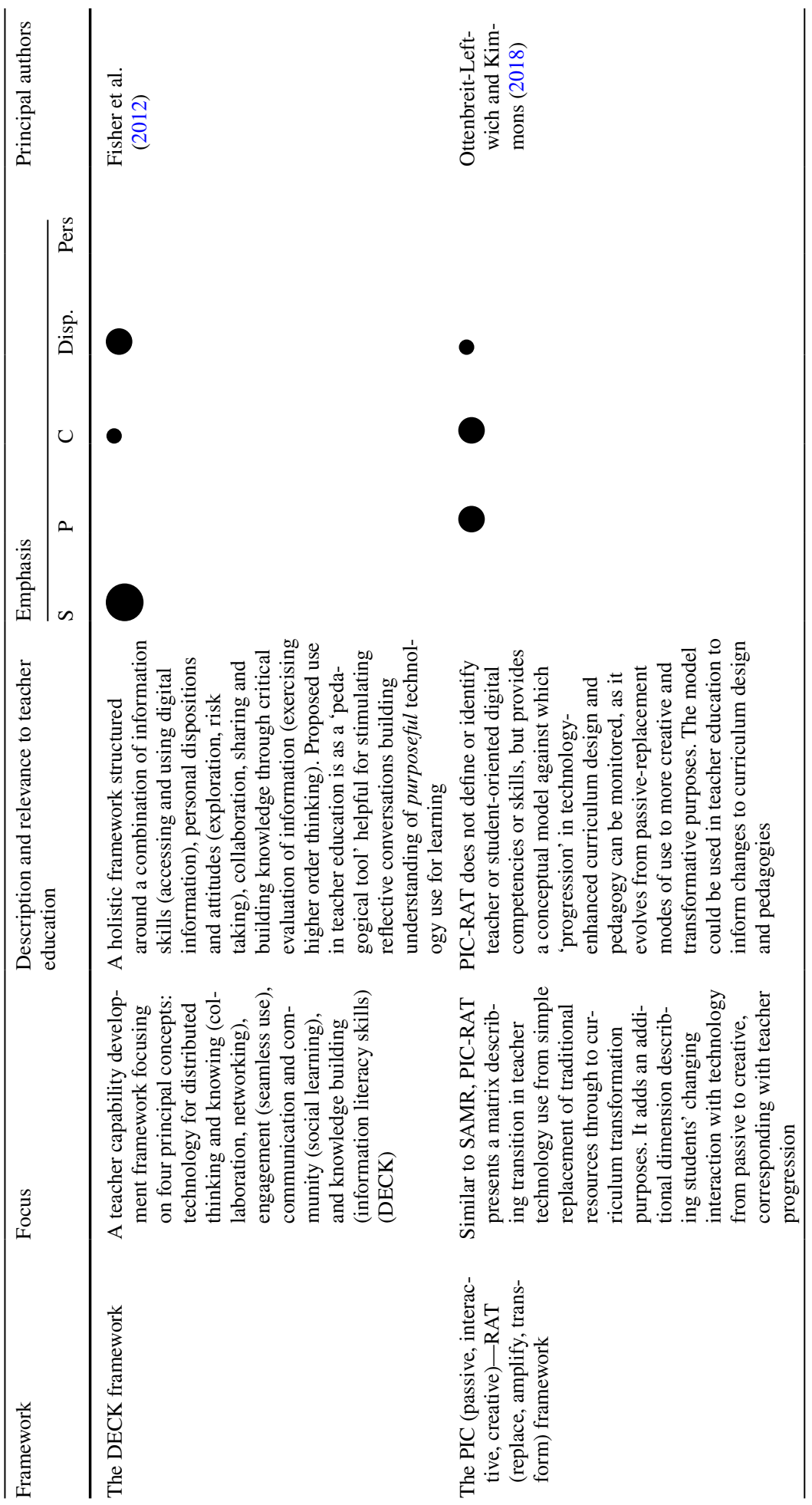




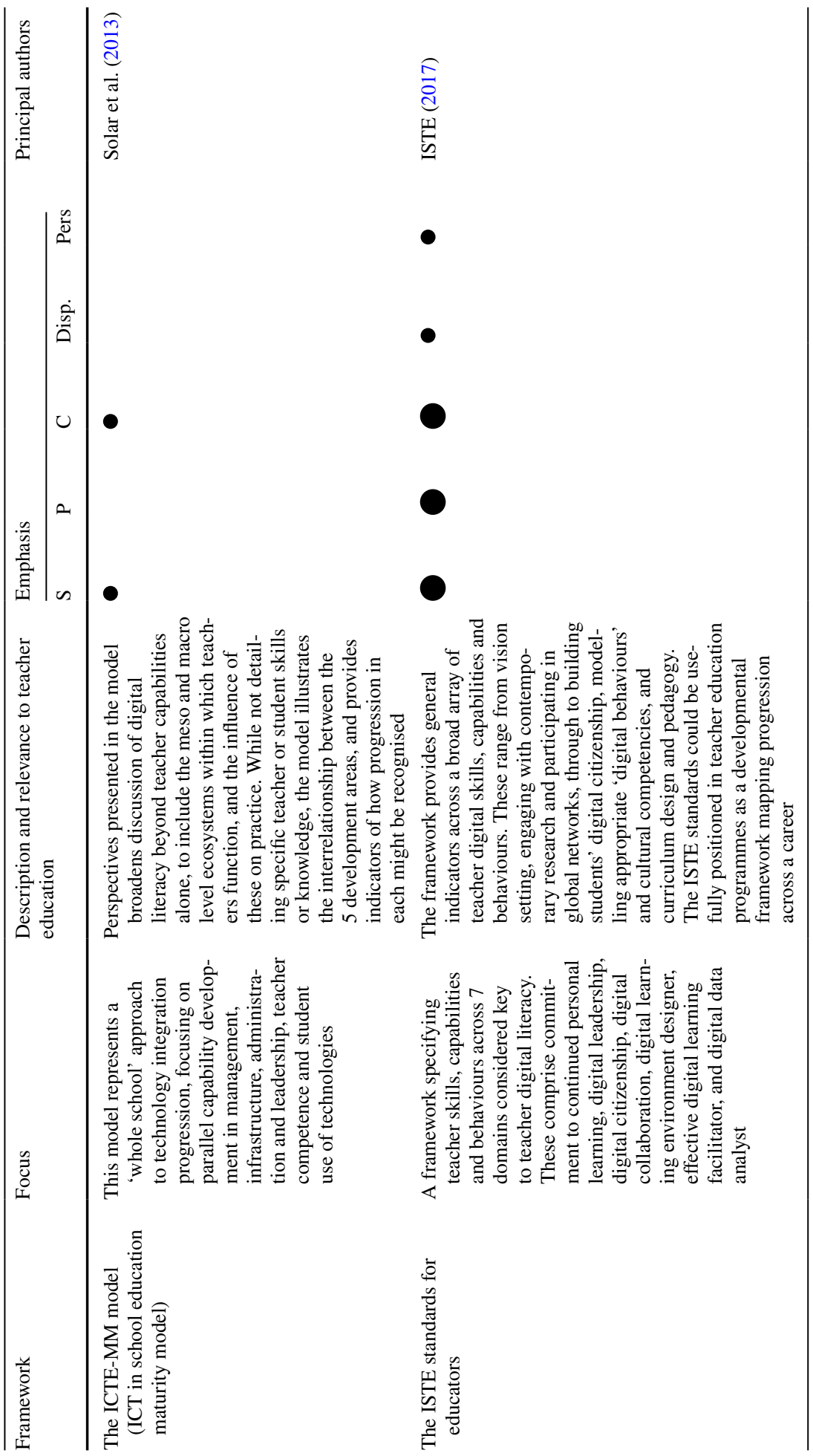

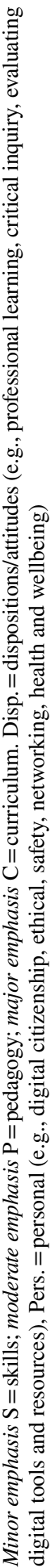




\section{References}

Admiraal, W., van Vuget, F., Kranenburg, F., Koster, B., Smit, B., Weijers, S., et al. (2016). Preparing preservice teachers to integrate technology into K-12 instruction: Evaluation of a technology-infused approach. Technology, Pedagogy and Education, 26(1), 105-120.

Aldosemani, T. (2019). Inservice teachers' perceptions of a professional development plan based on the SAMR model: A case study. The Turkish Online Journal of Educational Technology, 18(3), 46-53.

Amirault, R. (2015). Technology transience and the challenges it poses to higher education. The Quarterly Review of Distance Education, 16(2), 1-17.

Antonenko, P. (2014). The instrumental value of conceptual frameworks in educational technology research. Educational Technology Research and Development, 63, 53-71.

Battro, A., Calero, C., Goldin, A., Holper, L., Pezzatti, L., Shalóm, D., et al. (2013). The cognitive neuroscience of the teacher-student interaction. Mind, Brain and Education, 7(3), 177-181.

Baz, E., Balçıkanlı, C., \& Cephe, P. (2018). Introducing an innovative technology integration model: Echos from ELF pre-service teachers. Education and Information Technologies, 23, 2179-2200.

Beisel, C. (2017). New or novice teacher integration of mobile learning instruction. Doctoral dissertation, Walden University. Retrieved July 19, 2019, from https://scholarworks.waldenu.edu/dissertati ons/4349/.

Borthwick, A., \& Hansen, R. (2017). Digital literacy in teacher education. Are teacher educators competent? Journal of Digital Learning in Teacher Education, 33(2), 46-48.

Christ, W., \& Potter, W. (1998). Media literacy, media education, and the academy. Journal of Communication, 48(1), 5-15.

Ferrari, A. (2012). Digital competence in practice: An analysis of frameworks. Luxembourg: Publications Office of the European Union.

Fisher, T., Denning, T., Higgins, C., \& Loveless, A. (2012). Teachers knowing how to use technology: Exploring a conceptual framework for purposeful learning activity. Curriculum Journal, 23(3), 307-325.

Foulger, T., Buss, R., Wetzel, K., \& Lindsey, L. (2012). Preservice teacher education: Benchmarking a standalone EdTech course in preparation for change. Journal of Digital Learning in Teacher Education, $29(2), 48-58$.

Foulger, T., Graziano, K., Schmidt-Crawford, D., \& Slykhuis, D. (2017). Teacher educator digital competencies. Journal of Technology in Teacher Education, 25(4), 413-448.

Geer, R., White, B., Zeegers, Y., Wing, A., \& Barnes, A. (2017). Emerging pedagogies for the use of iPads in schools. British Journal of Educational Technology, 48(2), 490-498.

Gilster, P. (1997). Digital literacy. New York: Wiley.

Graziano, K., Herring, M., Carpenter, J., Smaldino, S., \& Finsness, E. (2017). A TPACK diagnostic tool for teacher education leaders. TechTrends, 61, 372-379.

Gruszczynska, A., \& Pountney, R. (2013). Developing the concept of digital literacy in the context of schools and teacher education. Enhancing Learning in the Social Sciences, 5(1), 25-36.

Gruszczynska, A., Merchant, G., \& Pountney, R. (2013). Digital futures in teacher education: Exploring open approaches towards digital literacy. The Electronic Journal of e-Learning, 11(3), 193-206.

Guzman, A., \& Nussbaum, M. (2009). Teaching competencies for technology integration in the classroom. Journal of Computer Assisted Learning, 25(5), 453-469.

Habowski, T., \& Mouza, C. (2014). Pre-service teachers' development of technological pedagogical content knowledge (TPACK) in the context of a secondary science teacher education program. Journal of Technology in Teacher Education, 22(4), 471-495.

Harris, J., Mishra, P., \& Koehler, M. (2009). Teachers' technological pedagogical content knowledge and learning activity types: Curriculum-based technology integration reframed. Journal of Research on Technology in Education, 41(4), 393-416.

Harrison, C. (2017). Critical internet literacy: What is it, and how should we teach it? Journal of Adolescent \& Adult Literacy, 61(4), 461-464.

Helsper, E. (2008). Digital inclusion: An analysis of social disadvantage and the information society. London: Department for Communities and Local Government.

Heydon, R. (2007). Making meaning together: Multi-modal literacy learning opportunities in an inter-generational art programme. Journal of Curriculum Studies, 39(1), 35-62.

Hilton, T. (2016). A case study of the application of SAMR and TPACK for reflection on technology integration into two social studies classrooms. The Social Studies, 107(2), 68-73.

Hinrichsen, J., \& Coombs, A. (2013). The five resources of critical digital literacy: A framework for curriculum integration. Research in Learning Technology, 21, 1-16. 
International Society for Technology in Education. (2017). ISTE standards for educators. Washington, DC: International Society for Technology in Education.

Janssen, J., Stoyanov, S., Ferrari, A., Punie, Y., Pannekeet, K., \& Sloep, P. (2013). Experts' views on digital competence: Commonalities and differences. Computers \& Education, 68, 473-481.

Kihoza, P., Zlotnikova, I., Bada, J., \& Kalegele, K. (2016). Classroom ICT integration in Tanzania: Opportunities and challenges from the perspectives of TPACK and SAMR models. International Journal of Education and Development using Information and Communication Technology, 12(1), $107-128$.

Kimmons, R., \& Hall, C. (2018). How useful are our models? Pre-service and practicing teacher evaluations of technology integration models. TechTrends, 62, 29-36.

Kleiner, B., Thomas, N., \& Lewis, L. (2007). Educational technology in teacher education programs for initial licensure. Washington, DC: National Center for Educational Statistics, U.S. Department of Education.

Klebansky, A., \& Fraser, S. (2013). A strategic approach to curriculum design for information literacy in teacher education: Implementing an information literacy conceptual framework. Australian Journal of Teacher Education, 38(11), 103-125.

Koehler, M., Mishra, P., \& Cain, W. (2013). What is technological pedagogical content knowledge (TPACK). Journal of Education, 193(3), 13-19.

Krause, J., \& Lynch, B. (2016). Preparing $21^{\text {st }}$ century educators: TPACK in physical education teacher education. Research Quarterly for Exercise and Sport, 87(2), 131-132.

Lim, C., Chai, C., \& Churchill, D. (2011). A framework for developing pre-service teachers' competencies in using technologies to enhance teaching and learning. Educational Media International, 48(2), 69-83.

Ludvigsen, S., \& Mørch, A. (2010). Computer-supported collaborative learning: Basic concepts, multiple perspectives, and emerging trends. In P. Peterson, E. Baker, \& B. McGaw (Eds.), The international encyclopedia of education (pp. 290-296). Oxford: Elsevier.

Lund, A., Furberg, A., Bakken, J., \& Engelien, K. (2014). What does professional digital competence mean in teacher education? Nordic Journal of Digital Literacy, 9(4), 281-299.

Mishra, P., \& Koehler, M. (2006). Technological pedagogical content knowledge: A framework for teacher knowledge. Teachers College Record, 6, 1017-1054.

Ndongfack, M. (2015). TPACK constructs: A sustainable pathway for teachers' professional development on technology adoption. Creative Education, 6, 1697-1709.

Otero, V., Peressini, D., Meymaris, K., Ford, P., Garvin, T., Harlow, D., et al. (2005). Integrating technology into teacher education: A critical framework for implementing reform. Journal of Teacher Education, 56(1), 8-23.

Ottenbreit-Leftwich, A., \& Kimmons, R. (2018). The K-12 educational technology handbook (1st ed.). Provo, UT: EdTech Books.

Ottestad, G., Kelentrić, M., \& Guðmundsdóttir, G. (2014). Professional digital competence in teacher education. Nordic Journal of Digital Literacy, 9(4), 243-249.

Palermiti, A., Servidio, R., Bartolo, M., \& Costabile, A. (2017). Cyberbullying and self-esteem: An Italian study. Computers in Human Behaviour, 69, 136-141.

Põldoja, H., Väljataga, T., Tammets, K., \& Laanpere, M. (2011). Web-based self and peer-assessment of teachers' educational technology competencies. Lecture Notes on Computer Science, 7048, 122-131.

Polly, D., Mims, C., Shepherd, C., \& Inan, F. (2010). Evidence of impact: Transforming teacher education with preparing tomorrow's teachers to teach with technology. Teaching and Teacher Education: An International Journal of Research and Studies, 26(4), 863-870.

Puentedura, R. (2006). Transformation, technology and education: A model for technology and transformation. Retrieved August 22, 2019 from http://hippasus.com/resources/tte/puentedura_tte.pdf.

Ravitch, S., \& Riggan, M. (2012). Reason and rigor: How conceptual frameworks guide research. Thousand Oaks, CA: Sage.

Reyes, V., Reading, C., Doyle, H., \& Gregory, S. (2017). Integrating ICT into teacher education programs from a TPACK perspective: Exploring perceptions of university lecturers. Computers \& Education, 115, 1-19.

Richards, D., Caldwell, P., \& Go, H. (2015). Impact of social media on the health of children and young people. Journal of Paediatrics and Child Health, 51(12), 1152-1157.

Salas-Pilco, S. (2013). Evolution of the framework for $21^{\text {st }}$ century competencies. Knowledge Management and e-Learning, 5(1), 10-24.

Säljö, R. (2010). Digital tools and challenges to institutional traditions of learning: Technologies, social memory and the performative nature of learning. Journal of Computer Assisted Learning, 26(1), 53-64. 
Sardone, N. (2019). Developing and engaging learning experience in preservice education. The Clearing House: A Journal of Educational Strategies, Issues and Ideas, 92(6), 235-245.

Shulman, L. (1986). Those who understand: Knowledge growth in teaching. Educational Researcher, 15(2), $1-22$.

Solar, M., Sabattin, J., \& Parada, V. (2013). A maturity model for assessing the use of ICT in school education. Journal of Educational Technology and Society, 16(1), 206-218.

Sutton, S. (2011). The preservice technology training experiences of novice teachers. Journal of Digital Learning in Teacher Education, 28(1), 39-47.

Tan, L., Chai, C., Deng, F., Zheng, C., \& Drajati, N. (2019). Examining pre-service teachers' knowledge of teaching multimodal literacies: A validation of the TPACK survey. Educational Media International, 56(4), 285-299.

Tsai, M. (2002). Do male and female students often perform better than female students when learning computers? A study of Taiwanese eight graders' computer education through strategic and cooperative learning. Journal of Educational and Computing Research, 26(1), 67-85.

United Nations Educational, Scientific and Cultural Organisation (UNESCO). (2011). ICT competency standards for teachers (version 2). Paris: UNESCO.

Voogt, J., \& McKenney, S. (2017). TPACK in teacher education: Are we preparing teachers to use technology for early literacy? Technology, Pedagogy and Education, 26(1), 69-83.

Webber, S., \& Johnston, B. (2000). Conceptions of information literacy: New perspectives and implications. Journal of Information Science, 26(6), 381-397.

Zurkowski, P. (1974). The information service environment relationships and priorities. Related paper no. 5. Washington, DC: National Commission on Libraries and Information Science.

Publisher's Note Springer Nature remains neutral with regard to jurisdictional claims in published maps and institutional affiliations.

Garry Falloon is the Director of International Engagement and Professor of STEM Education and Digital Learning, Macquaire School of Education, Macquarie University. Prior to this he was Professor of Digital Learning in the Faculty of Education at Waikato University in Hamilton, New Zealand (until moving to Macquarie mid 2017). In his career to date he has held a number of education research and digital project leadership roles in the private sector and government, and has 20 years experience serving in school teaching and leadership positions. 